\title{
Borderline personality disorder in the elderly: brief review
}

\begin{abstract}
Borderline personality disorder (BPD) is a prevalent condition today. The studies carried out about its evaluation and treatment are aimed at the adolescent and adult population, however, there is not enough information in the elderly. In these, symptoms related to emotional instability and interpersonal performance predominate, different from the clinic of the categorical prototype in young people. No further research has been developed on effective treatment for this age group with personality disorder; however, it seems that the use of psychotropic drugs and psychotherapy is useful for those with associated comorbidities.
\end{abstract}

Keywords: borderline personality disorder, elderly
Volume 3 Issue 5 - 2018

\author{
Glauco Valdivieso-Jiménez \\ Psychiatrist, Psychotherapist, Center for Research, Teaching and \\ Comprehensive Care in Mental Health (CENTIDOS) Lima, Peru \\ Correspondence: Glauco Valdivieso Jiménez, Psychiatrist, \\ Psychotherapist, Treatment Program for Personality Limit \\ Disorder according to the model of Dialectical Behavioral \\ Therapy (DBT), Center for Research, Teaching and \\ Comprehensive Care in Mental Health (CENTIDOS) Lima, Jr. \\ Arequipa 133, Magdalena del Mar, Lima \\ Email glawco.valdivieso@unmsm.edu.pe
}

Received: July 29, 2018 | Published: October 16, 2018

\section{Introduction}

Mental health problems in older adults are manifested differently than in young people, in addition the history of personality disorders that are not evaluated in time in any age group are a factor that complicates the clinical evolution of all patients. which motivates to carry out a review about the findings through different research work on the symptomatology, evaluation and treatment of these patients. This could contribute to the clinician to make a more detailed exploration of a probable borderline personality disorder in the elderly.

The main aim for this brief review is to standardize the knowledge obtained according to available information on the predominant symptomatology in older adults with a diagnosis of borderline personality disorder, the current status of the evaluation criteria and clinical issues.

\section{Methods}

A review of the current literature was carried out by searching for review articles and clinical research in Medline and Scielo, introducing the keys "borderline personality disorder", "BPD", "old age", and "elderly". The information was selected from 1996 to 2018. The critical review was made by the same author.

\section{General view}

The personality is defined as a biological, psychological, social, cultural and spiritual construct that governs the style tendencies in the emotions, cognitions and acts of subjects. It is shaped as you experience different situations in life (character) under an innate predisposition of action (temperament). The personality disorder is referred to the dysfunctionality of the predominant prototypical features present most of the time, chronically, alters interpersonal relationships, is alien to the culture of the subject and generates great discomfort. ${ }^{1,2}$

On the other hand, borderline personality disorder (BPD) has a symptomatological core that is emotional instability, which leads the person's mental life leading to constant impulsive acts. Its prevalence in clinical samples within the categories of personality disorders in general, is $30-60 \%$. It occurs more frequently in adolescent and adult women, although when presented in males there is the same severity. ${ }^{2,3}$

At present, there is little information about the role of aging in the personality of individuals. Despite this, some studies report that the features and their characteristics that lead to classify it as a disorder, tend to decrease with age. The experience of some clinicians contradicts this, referring that, above all, in type B personality disorders, there is a moderate increase in risk patterns. Clinical experience suggests that BPD is more prevalent in the elderly than previously recognized, which agrees with limited available research. The prevalence of BPD in adults was $1.3 \%$ and $1.4 \%$ as indicated by a study. 4,5

Although the prevalence of BPD is higher in clinical populations than in the community, its information in psychiatric populations of advanced age is highly variable. One of the few studies like that of Widiger and Seidlitz (2002) concluded that the prevalence for the diagnosis of some personality disorder was $10 \%-63 \%$, in the same way Stevenson (2011) found that $60 \%$ of a small sample met criteria for personality disorder. ${ }^{6,7}$

\section{Semiology}

The main symptoms of BPD are impulsiveness, aggressiveness, suicidality, inappropriate anger, chaotic relationships, fear of rejection, emptiness feeling and cognitive / perceptual symptoms (micro psychosis, dissociation) being triggered by a constant pattern of emotional instability and this in turn, arises from an alteration of self and interpersonal functioning. However, these symptoms are based on the prototype found in the standard of adolescent patients and young adults. ${ }^{8-10}$

In the prospective study by Zanarini (2012), McLean Adult Development Study (MSAD), found a pattern of improvement for some features of BPD over time, on all those corresponding to impulsivity and suicidal-parasuicidal behavior that dominates in adolescence, however these findings cannot be extrapolated to other populations because of the lack of them, but it is presumed that the experience throughout life in different contexts that test the maturity of people, are a stabilizing factor. ${ }^{11}$ 
In old age, significantly lower levels of impulsivity, self-harm and substance use disorders are reported in the elderly population with BPD compared to younger adults. Because the most studied populations have always been adolescents and adults, when paying more attention to impulsivity there is less sensitivity in the diagnosis of personality disorders as age increases, based on the diagnostic guidelines available to all mental health professionals. However, selfharm occurs in younger patients, and those in the elderly, can occur in response to stress factors, especially as lack of psychosocial support. Suicidal threats are frequent, while suicidal gestures are much less so. Despite being uncommon, suicide attempts in elderly tend to be life threatening. ${ }^{12-15}$

On the other hand, it has been described that the symptoms that persist with age are emotional instability and dysfunctional interpersonal relationships characterized by lack of empathy, generating chaotic environments in the home, work and other places corresponding to the context of the elderly. It has also been seen that there is a high prevalence of depression in old age that is often confused with the variable mood symptoms of BPD, assuming that its presence could affect its course and contribute to the predominance of negative affectivity. ${ }^{16-18}$

In the elderly, despite the psychic symptoms, there is a lower incidence of suicidal behavior, but a greater association with somatization, as well as devaluation in the content of the thought regarding life, its current condition and in some cases nonconformity with the treatment or health services. The frequent use of somatization is often expressed in dramatic and demanding complaints of medical attention. Studies pointed out that medical and psychopharmacological interventions associated with somatization can lead to prolonged admissions and generate conflicts with mental health staff (Table 1). 19-21

Table I Symptomatology in clinical groups in adolescence, adulthood and old age with BPD

\begin{tabular}{ll}
\hline $\begin{array}{l}\text { Main symptoms in adolescents } \\
\text { young adults (prototypical) }\end{array}$ & Main symptoms in old age \\
\hline Emotional instability & $\begin{array}{l}\text { Emotional instability } \\
\text { Impulsivity }\end{array}$ \\
& $\begin{array}{l}\text { Dysfunctional interpersonal } \\
\text { relationships }\end{array}$
\end{tabular}

Aggressiveness

Negative affectivity: depression

Suicidality: suicidal behavior and self-harm Somatic symptoms

Inappropriate anger,

Alteration in the content of thought

Chaotic relationships,

Fear of rejection

Chronic vacuum sensation

Cognitive/perceptual symptoms (micro

psychosis, dissociation)

\section{Difficulties in assesment}

There are many factors that prevent an adequate diagnosis in older adults. Of these we have the fact that there are no instruments available for evaluation and focus on young populations, absence of relatives that prevent the collection of biographical data, the coexistence of neurological / systemic diseases that overlap the diagnoses. There are only a few studies that apply the ICD 10 and
DSM 5 diagnostic guides with non-significant samples. The difficulty is also found in the complexity of the course and evolution of the personality disorder considering it as a single entity since, according to the dimensional vision of it, it is opposed to the diagnostic categories and gives importance to the levels of severity as long time This is essential within the current discussions on the conceptualization of the personality and its disorder, since it would lead to the assumption that, if it is a variable alteration dimension in time, the severity of the symptoms would be less identifiable in the studies that are made cross-section, despite having been diagnosed in the past. ${ }^{22,23}$

\section{Treatment}

The management of personality disorder is of increasing interest in the field of mental health. The evidence is more numerous in borderline personality disorder in which psychotherapeutic and psychopharmaceutical models are included for the relief of symptoms. ${ }^{24}$

It has been described that the lack of management in personality disorder, implies worse general clinical evolution in patients with diagnoses of comorbidity, being the case of major depression that is the most common in the elderly. ${ }^{25,26}$

There are two publications of studies aimed to treatment of personality disorders in the elderly population. The first study was a randomized controlled trial in depressed elderly patients who had at least one comorbid personality disorder according to the Structured Clinical Interview for DSM-IV for Axis II (SCID-II) who did not respond to an antidepressant drug initially. Two groups were taken in which the pharmacological treatment was compared and in another adjunctive with dialectical behavioral therapy (DBT). However, the addition of DBT did not significantly improve depressive symptoms compared to medication alone. It is likely that there was a diagnostic confusion between personality disorder and depression. ${ }^{27}$

The second study evaluated the efficacy of scheme therapy in 31 elderly patients with chronic depression and a personality disorder. It was found reduction of depressive symptoms and dysfunctional thinking schemes. ${ }^{28}$ Therefore, taking into account the effectiveness of comprehensive treatment, ie the use of psychotropic drugs aimed at symptoms or comorbidities, and cognitive behavioral therapy (DBT) and psychodynamic psychotherapy, may be useful in this population in the same way as in younger populations. Its effectiveness should be studied further. ${ }^{29}$

The combination of antidepressants with DBT has been described, the result of which was significant with respect to the improvement in interpersonal sensitivity and interpersonal aggression, in the posttreatment and 6-month follow-up compared with antidepressants alone. On the other hand, the addition of DBT did not significantly improve depressive symptoms in those with antidepressants alone. In both conditions, at least half of the subjects were in remission after having started medication, which makes it probable that there was confusion in the diagnosis with comorbid depression, because in previous studies it has been estimated that the medication in itself does not produce significant results. ${ }^{30}$

\section{Discussion}

It is important to emphasize that the studies to date have not provided us with reliable and truthful information about the phenomenology of BPD. It is likely that this is due to the heterogeneity 
of the investigations, the small samples of population, the scarce prior knowledge of the semiological evolution of personality disorders in general and which in turn influences the absence of sensitive instruments that manage to identify traits of dysfunctional personality in old age.

The controversy between categorical and dimensional vision is another reason it could affect the timely identification of personality disorders, as long as it continues to be considered in official manuals of general management among mental health professionals, this inefficiency and clinical ignorance of this age group will remain a vicious circle.

Regarding the limitations of the review, there is little information about borderline personality disorder in the elderly, so the most significant articles with more concise results that could be of better help for the preparation of the brief review have been chosen.

It is suggested to perform more studies on psychopathological findings in older adults with pathological personality or personality disorders in community samples, because it is difficult to find mental health problems related to personality as a first choice of elderly patients in hospitals or private clinics. This would allow to obtain more reliable epidemiological information that would help the clinician to identify a risk factor to complicate other mental comorbidities.

\section{Conclusion}

According to the information that is available to date, the following conclusions of borderline personality disorder in old age are stated:

i. Predominance of emotional instability and dysfunctional interpersonal relationships.

ii. Predominance of depressive symptoms: depressive mood, devaluative thinking, somatization.

iii. Decrease in impulsivity, therefore, lower suicidality rate.

iv. There is absence of instruments available for the evaluation of borderline personality disorder in old age.

v. Contrast in the model of categorical and dimensional diagnosis that limits the appropriate clinical judgment.

vi. It is recommended to carry out more studies based on the personality dimension, taking into account factors specific to the context of the individual.

vii. There is little evidence of the treatment of personality disorders in older adults, but psychotherapy seems to help reduce mood symptoms.

\section{Financing}

Self-financed.

\section{Acknowledgement}

None.

\section{Conflict of interest}

The author declares that there is no conflict of interests.

\section{References}

1. Koldobsky NMS. Trastornos de Personalidad. Aspectos generales para su tratamiento. Editorial Polemos. Primera Edición. Buenos Aires, Argentina; 2009 .
2. American Psychiatric Association. DSM-5: Manual Diagnóstico Y Estadístico De Los Trastornos Mentales. 5th ed. Madrid. Editorial Médica Panamericana; 2014.

3. Koldobsky NMS. Trastorno borderline de la personalidad: Un desafío clínico. Editorial Polemos. Primera Edición. Buenos Aires, Argentina; 2005.

4. Beatson J, Broadbear JH, Sivakumaran H, et al. Missed diagnosis: The emerging crisis of borderline personality disorder in older people. Aust $N$ Z J Psychiatry. 2016;50(12):1-7.

5. Lenzenweger MF. Epidemiology of personality disorders. Psychiatric Clinics of North America. 2008;31(4):395-403.

6. Widiger TA, Seidlitz L. Personality, psychopathology and aging. Journal of Research in Personality. 2002;36(4):335-362.

7. Stevenson J, Datyner A, Boyce P, et al. The effect of age on prevalence, type and diagnosis of personality disorder in psychiatric inpatients. Int $J$ Geriatr Psychiatry. 2011;26(9):981-987.

8. Zanarini M. Borderline Personality Disorder. Taylor \& Francis Group. New York; 2005.

9. Borderline Personality Disorder. The NICE Guideline on Treatment and Management. National Collaborating Centre for Mental Health. The British Psychological Society and Royal College of Psychiatry; 2009.

10. Livesley J. Integrated treatment: A conceptual framework for an Evidencebased approach to the treatment of personality disorder. J Pers Disord. 2012;26(1):17-42.

11. Zanarini MC, Frankenburg FR, Reich D, et al. Attainment and stability of sustained symptomatic remission and recovery among patients with borderline personality disorder and axis II comparison subjects: A 16-year prospective follow-up study. The Am J of Psychiatry. 2012;169(5):476483.

12. Cruitt PJ, Oltmanns TF. Age-related outcomes associated with personality pathology in later life. Curr Opin Psychol. 2018; 21:89-93.

13. Oltmanns TF, Balsis S. Personality disorders in later life: questions about the measurement, course and impact of disorders. Annual review of clinical psychology. 2011;7:321-349.

14. Avari J, Mahgoub N, Mittal S, et al. A case series of elderly patients with borderline personality disorder and self-injurious behavior. The American Journal of Geriatric Psychiatry. 2011;19:S84-S85.

15. Sadavoy J. Personality disorder in old age: Symptom expression. Clinical Gerontologist. 1996;16:19-36.

16. Richa S, Ibrahim C. Course and stability of personality disorders in the elderly: A review. International Journal of Neuro psychopharmacology. 2012;15:238-239.

17. Gunderson JG, Stout RL, McGlashan TH, et al. Ten-year course of borderline personality disorder: Psychopathology and function from the Collaborative Longitudinal Personality Disorders study. Arch Gen Psychiatry. 2011;68(8):827-837.

18. Shea MT, Edelen MO, Pinto A, et al. Improvement in borderline personality disorder in relationship to age. Acta Psychiatrica Scandinavica. 2009;119(2):143-148.

19. Arens EA, Stopsack M, Spitzer C, et al. Borderline personality disorder in four different age groups: A cross-sectional study of community residents in Germany. J Pers Disord. 2013;27(2):196-207.

20. Sansone RA, Watts DA, Wiederman MW. Pain and pain catastrophizing among internal medicine outpatients with borderline personality symptomatology: A cross-sectional self-report survey. Prim Care Companion CNS Disord. 2013;15(5).

21. Scheiderer EM, Wood PK, Trull TJ. The comorbidity of borderline personality disorder and posttraumatic stress disorder: revisiting the 
prevalence and associations in a general population sample. Borderline Personal Disord Emot Dysregul. 2015;2:11.

22. Stevenson J, Meares R and Comerford A. Diminished impulsivity in older patients with borderline personality disorder. The Am J Psychiatry. 2003;160(1):165-166.

23. Stepp SD, Pilkonis PA. Age-related differences in individual DSM criteria for borderline personality disorder. J Pers Disord. 2008;22(4):427-432.

24. Torgersen S, Kringlen E, Cramer V. The prevalence of personality disorders in a community sample. Arch Gen Psychiatry. 2001; 58(6):590-596.

25. Alphen SPJ, Dijk M, Videler AC, et al. Personality Disorders in Older Adults: Emerging Research Issues. Curr Psychiatry Rep. 2015;17(1):538.

26. Lynch TR, Morse JQ, Mendelson T, et al. Dialectical behavior therapy for depressed older adults: a randomized pilot study. Am J Geriatr Psychiatr. 2003;11(1):33-45.
27. Kindynis S, Burlacu S, Louville P, et al. Effect of schema focused therapy on depression, anxiety and maladaptive cognitive schemas in the elderly. Encéphale. 2013;39(6):393-400.

28. Lynch TR, Cheavens JS, Cukrowitz KC, et al. Treatment of adults with co-morbid personality disorder and depression: a dialectical behaviour therapy approach. Int J Geriatr Psychiatr. 2007;22(2):131-143.

29. Videler AC, Rossi G, Schoevaars MH, et al. Effects of schema group therapy in older outpatients: a proof of concept study. Int Psychogeriatr. 2014;26(10):1709-1717.

30. Alphen SPJ, Tummers JHA, Derksen JJL. Reaction to 'Treatment of older adults with co-morbid personality disorder and depression: a dialectical behavior therapy approach'. Int J Geriatr Psychiatr. 2007;22(7):702-703. 